\title{
Formulation and Evaluation of Spray-Dried Esomeprazole Magnesium Microspheres
}

\author{
Achin Jain, MN Ravi Teja, Laxman Pariyani, V Balamuralidhara and N Vishal \\ Gupta*
}

Department of Pharmaceutics, JSS College of Pharmacy, JSS University, Sri Shivarathreeshwara Nagar, Mysore - 570015 , Karnataka, India.

*For correspondence: Email: vkguptajss@gmail.com; Tel: +91-821-2548353

Received: 4 September 2012

Revised accepted: 19 April 2013

\begin{abstract}
Purpose: To prepare and evaluate in vitro mucoadhesive esomeprazole magnesium microspheres for the treatment of Zollinger Ellison syndrome.

Methods: The microspheres were prepared by spray drying technique using locust bean and xanthan gums as polymers. Esomeprazole magnesium was entrapped in the microspheres at various polymer/cross-linking ratios. Glutaraldehyde was used to cross-link the gums. The microspheres were evaluated for their micromeritic properties and in vitro release. as well as by Fourier transform infrared (FTIR), differential scanning calorimetry (DSC) and scanning electron microscopy (SEM).

Results: The microspheres were discrete, spherical, and showed good drug entrapment efficiency (60.5 - 92.3\%). FTIR and DSC results indicate that the drug was compatible with the polymers used. Amongst all the formulations, F6 (drug:locust bean gum:xanthan gum, 1:2:2) showed the most suitable sustained release properties with $99.8 \%$ of drug released at the end of $12 \mathrm{~h}$.

Conclusion: Microspheres prepared using locust bean and xanthan gums can be used as a sustained release delivery system for esomeprazole magnesium.
\end{abstract}

Keywords: Spray drying, Microspheres, Esomeprazole magnesium, Sustained release

Tropical Journal of Pharmaceutical Research is indexed by Science Citation Index (SciSearch), Scopus, International Pharmaceutical Abstract, Chemical Abstracts, Embase, Index Copernicus, EBSCO, African Index Medicus, JournalSeek, Journal Citation Reports/Science Edition, Directory of Open Access Journals (DOAJ), African Journal Online, Bioline International, Open-J-Gate and Pharmacy Abstracts

\section{INTRODUCTION}

Zollinger-Ellison syndrome is a condition in which the patient suffers from ulcers in the upper digestive tract (that do not respond to medications), excessive gastric acid secretion and diarrhea. The increased acid secretion results in inflammation and ulcers in the stomach and lower food pipe, and diarrhea [1].

Esomeprazole is chemically bis(5-methoxy-2[(S)-[(4-methoxy-3,5-dimethyl-2 pyridinyl) methyl] sulfinyl]-1-H-benzimidazole-1-yl), a compound that inhibits gastric acid secretion. Esomeprazole is inactive at neutral $\mathrm{pH}$, but at $\mathrm{pH}<5$ rearranges to two charged cationic forms (a sulphenic acid and a sulphenamide configurations) that react covalently with $\mathrm{SH}$ groups of the $\mathrm{H}^{+} \mathrm{K}^{+}$ATPase enzyme and inactivate it irreversibly, especially when two molecules of omeprazole react with one molecule of the enzyme. Its bioavailability is $89 \%$ and has a plasma elimination half life of 1.5 $\mathrm{h}[2]$.

Various natural polymers such as locust bean and xanthan gums, chitosan and gelatin have been used to develop drug delivery systems for entrapping and delivering drugs orally [3]. Biodegradable microspheres can be prepared from certain synthetic as well as natural 
polymers. Biodegradable carrier matrices can be designed to deliver the therapeutic agent for periods ranging from a few days to a few years [4]. The use of natural polymers such as agar, guar gum, chitosan, gelatin, carboxy methyl cellulose, xanthan gum, karaya gum, sodium alginate and locust bean gum to delivery drugs promises to be an active area of research due to their natural origin, easy availability, cost effectiveness, ecofriendliness, possibility of chemical modifications and are potentially biodegradable [5].

Locust bean gum powder is obtained from the Carob (Ceratonia siliqua) tree. It consists of high molecular weight (approximately 50,000 $3,000,000$ ) polysaccharides composed of galactomannans; the mannose: galactose ratio is about $4: 1$. It is safe and acceptable for use in food and does not show any hazards to health [6].

Xanthan gum is a polysaccharide produced by fermentation of glucose or sucrose, mainly corn sugar, by Xanthomonas campestris bacterium to produce a clear and sticky liquid which is dried to obtain gum. It helps in stabilizing emulsion by increasing viscosity, suspending insoluble solids in various preparations, retarding drug release, and hence useful in sustaining drug release $[7,8]$. The main aim of the present study is to develop and evaluate esomeprazole magnesium microspheres using the natural polymers, locust bean and xanthan gums and spray drying technique.

\section{EXPERIMENTAL}

\section{Materials}

Esomeprazole magnesium trihydrate and Eudragit ${ }^{\circledR}$ L100 were gifts from Dr. Reddy's Laboratories Ltd, Hyderabad, India. Locust bean gum and xanthan gums were obtained from Sigma Aldrich, USA. Glutaraldehyde was purchased from Loba Chemie, India. All other materials used were of analytical grade.

\section{Preparation of microspheres}

Mucoadhesive microspheres were prepared by spray drying technique. An aqueous solution containing different combinations/ratios of the polymers (Table 1) were prepared by dissolving locust bean and xanthan gums in distilled deionized water. The drug (1 g), previously dissolved in $100 \mathrm{ml}$ of absolute methanol, was added to the polymer solution and sonicated using Ultra sonicator (1204 AU-Vibracell, USA) to obtain a homogeneous mixture. A crosslinking agent, glutaraldehyde $(0-0.30 \mathrm{ml})$, was added to the homogenized solution and spray dried by spraying through the nozzle of a spray-dryer (JISL, LSD- 48 mini spray dryer, India) at input temperature of $115-117^{\circ} \mathrm{C}$, output temperature of $80-85{ }^{\circ} \mathrm{C}$ at $2 \%$ feed rate and vacuum pressure of $35 \mathrm{psi}\left(2.4 \mathrm{~kg} / \mathrm{cm}^{2}\right)$. The resulting microspheres were ollected from the spray dryer and kept in a desiccator containing silica gel pending further tests [9].

\section{Enteric coating of microspheres}

An enteric coating solution $(4.0 \% \mathrm{w} / \mathrm{v})$ containing Eudragit ${ }^{\circledR}$ L100 was dissolved in a mixture of ethanol and dicholoromethane (1:1). Di-butyl phthalate (15\%w/w based on the polymer) was added as plasticizer stirred with a magnetic stirrer for sufficient period of time $(1 \mathrm{~h})$. The previously prepared microspheres was added to the solution, mixed well, and the mixture spraydried by spraying through the nozzle of a spraydryer (Lab Spray drier, JISL, Mumbai, India). The process conditions were set as follows: Inlet temperature $60-65^{\circ} \mathrm{C}$, outlet temperature 50$55^{\circ} \mathrm{C}$ at $2 \%$ feed rate and vacuum pressure of 35 psi $\left(2.4 \mathrm{~kg} / \mathrm{cm}^{2}\right)$. The coated microspheres were retrieved from the spray dryer.

\section{Determination of drug entrapment efficiency and yield}

The drug entrapment efficiency (DEE) and yield of coated microspheres were computed by Eqs 1 and 2 , respectively.

DEE $=(\mathrm{Pc} / \mathrm{Tc}) \times 100$

where $\mathrm{Pc}$ is actual drug content and $\mathrm{Tc}$ is the theoretical drug content. units were analyzed in triplicate.

$$
\text { Yield }(\%)=\left(W_{1} / W_{2}\right) \times 100
$$

where $W_{1}$ is the weight of microspheres and $W_{2}$ is the total weight of drug and polymer used in formulating the microspheres.

\section{Particle size analysis}

The particle size of the microspheres was determined by optical microscopy method. Approximately 100 microspheres were counted using a calibrated optical microscope (Labomed CX RIII, Ambala, India).

\section{Swelling studies}

The swelling ability of the uncoated microspheres in physiological media was determined by immersing an accurately weighed amount (500 $\mathrm{mg}$ ) of microspheres in a little excess of $100 \mathrm{ml}$ of phosphate buffer ( $\mathrm{pH} \mathrm{6.8)}$ ) and kept for $24 \mathrm{~h}$. Eq 3 was to compute the degree of swelling. 


$$
S_{s w}=\left(W_{s}-W_{0} / W_{0}\right) \times 100
$$

where $S_{\text {sw }}=$ percent swelling of microspheres, $\mathrm{W}_{\mathrm{o}}=$ initial weight of microspheres, $\mathrm{W}_{\mathrm{s}}=$ weight of microsphere after swelling [10].

\section{Differential scanning calorimetry (DSC)}

DSC study was carried out to detect possible polymorphic transition during the preparation process. DSC measurements were performed on a differential scanning calorimeter (DSC, DuPont 9900 , USA) with a thermal analyzer. The samples were heated in an atmosphere of nitrogen at a constant heating rate of $10{ }^{\circ} \mathrm{C} / \mathrm{min}$ in the range of $20-220^{\circ} \mathrm{C}$.

\section{Fourier transform infrared spectroscopy (FT- IR)}

The samples of pure drug and formulation F6 were dispersed in $200 \mathrm{mg}$ of $\mathrm{KBr}$ powder and compressed into pellets at a pressure of 6000 $\mathrm{kg} / \mathrm{cm}^{2}$ and analyzed. Spectral measurements were obtained by powder diffuse reflectance on a FT-infrared spectrophotometer (Shimadzu, FT-IR 8400S, Japan).

\section{Scanning electron microscopy (SEM)}

Scanning electron microscopy (Joel- LV-5600, USA) was applied to obtain photomicrographs which were used to identify and confirm the surface topography of the microspheres.

\section{In vitro release studies}

The release profiles of the formulations were determined using USP dissolution apparatus XXIV-Type II (TDT-08T, Electro Lab, Mumbai). The microspheres were enclosed in a muslin cloth which was then tied to the lowest part of the paddle. The paddle was then rotated $(100 \mathrm{rpm})$ immersed in $\mathrm{pH} 1.2 \mathrm{HCl}$ buffer and for $2 \mathrm{~h}$, and immediately transferred to a phosphate buffer (pH 6.8) medium and tested for $10 \mathrm{~h}$ at $37 \pm 0.5$ ${ }^{\circ} \mathrm{C}$. Aliquots of $5 \mathrm{ml}$ were withdrawn hourly over a period of $12 \mathrm{~h}$. Drug content was determined spectrophotometrically (UV 1601 A Shimadzu, Japan) at $302.13 \mathrm{~nm}$. The studies were carried out in triplicate, and the release data obtained were fitted into various release models, namely, zero order (Eq 4), first order (Eq 5), Higuchi (Eq 6 ) and Korsmeyer-Peppas (Eq 7).

$$
\begin{aligned}
& Q_{t}=K_{o} t \ldots \ldots \ldots \ldots \ldots \ldots(4) \\
& \ln Q_{t}=\ln Q_{o}-K_{1} t \ldots \ldots \ldots(5) \\
& Q_{t}=K_{h} t^{1 / 2} \ldots \ldots \ldots \ldots \ldots \ldots(6) \\
& M_{t} / M_{o}=K_{p} t^{n} \ldots \ldots \ldots \ldots \ldots(7)
\end{aligned}
$$

Where $\mathrm{K}$ is constant, $\mathrm{Qt}$ is the amount of drug released at time, 0 or $\mathrm{t}$, Mt is also the amount of drug diffused at tome, 0 or t tTo determine release mechanism, the parameters $n$ and $k$ in the Korsmeyer-Peppas equation were computed [11].

\section{Statistical analysis}

Data were assessed for statistical significance by Student t-test at $95 \%$ level of confidence level using Sigmaplot 11.

\section{RESULTS}

\section{Drug entrapment efficiency and \% yield}

With increase in the concentration of crosslinking agent, DEE increased, as shown in Table 1. DEE ranged from $60-92 \%$. Low DEE was observed for uncrosslinked microspheres (F1 - F3) The difference was significant $(p<0.05)$. Microsphere yield ranged from $30-65 \%$.

\section{Particle size analysis}

The size of particles varied with the concentration of polymer used and the feed rate. Particle size ranged from 2 - $8 \mu \mathrm{m}$.

\section{Swelling studies}

Swelling results are shown in Table 1, and they indicate that as polymer concentration rose, the degree of swelling also increased $(p<0.05)$.

\section{Differential scanning calorimetry (DSC)}

The DSC thermograms obtained are displayed in Figure 1. It shows that the decomposition temperature of drug was $177.3{ }^{\circ} \mathrm{C}$ and formulation $\mathrm{F} 6$ was $171.2^{\circ} \mathrm{C}$.

\section{Fourier Transform Infrared spectroscopy (FT- IR)}

The FT-IR spectra of the pure drug microsphere formulation (F6) are shown in Figure 2. The broad peak at $3217.01 \mathrm{~cm}^{-1}$ in the spectra of the pure drug corresponds to $\mathrm{C}=\mathrm{N}$ group. The peak at $108.32 \mathrm{~cm}^{-1}$ corresponds to $\mathrm{C}=\mathrm{S}$ boding. The peaks at $1613.2 \mathrm{~cm}^{-1}$ and $1581.2 \mathrm{~cm}^{-1}$ indicate the presence of carbonyl group. The drug and polymers employed were found to be compatible as similar peaks were observed with minor differences. 
Table 1: Characterization of mucoadhesive microspheres (mean $\pm S D, n=3$ )

\begin{tabular}{lcccccc}
\hline $\begin{array}{l}\text { Batch } \\
\text { code }\end{array}$ & $\begin{array}{c}\text { D:L:X } \\
\text { ratio }\end{array}$ & $\begin{array}{c}\text { Crosslinking } \\
\text { agent }(\% \mathrm{v} / \mathbf{v})\end{array}$ & Yield $(\%)$ & $\begin{array}{c}\text { DEE } \\
(\%)\end{array}$ & $\begin{array}{c}\text { Particle } \\
\text { size }(\boldsymbol{\mu m})\end{array}$ & $\begin{array}{c}\text { Swelling } \\
(\%)\end{array}$ \\
\hline F1 & $1: 2: 0$ & 0.0 & $30.3 \pm 1.0$ & $60.5 \pm 2.5$ & $5.32 \pm 1.23$ & $200 \pm 6$ \\
F2 & $1: 2: 1$ & 0.0 & $32.5 \pm 1.2$ & $72.5 \pm 3.2$ & $5.68 \pm 1.56$ & $226 \pm 7$ \\
F3 & $1: 2: 2$ & 0.0 & $45.1 \pm 1.5$ & $81.2 \pm 3.5$ & $8.23 \pm 2.11$ & $264 \pm 8$ \\
F4 & $1: 2: 0$ & 0.15 & $39.2 \pm 1.1$ & $71.6 \pm 4.6$ & $4.45 \pm 1.56$ & $163 \pm 5$ \\
F5 & $1: 2: 1$ & 0.15 & $49.6 \pm 1.7$ & $83.2 \pm 5.8$ & $4.61 \pm 1.42$ & $172 \pm 5$ \\
F6 & $1: 2: 2$ & 0.15 & $52.5 \pm 2.4$ & $86.5 \pm 5.6$ & $5.05 \pm 1.53$ & $185 \pm 4$ \\
F7 & $1: 2: 0$ & 0.30 & $42.5 \pm 1.7$ & $72.5 \pm 4.8$ & $2.13 \pm 0.92$ & $116 \pm 4$ \\
F8 & $1: 2: 1$ & 0.30 & $56.3 \pm 2.3$ & $83.9 \pm 6.1$ & $3.66 \pm 1.12$ & $128 \pm 6$ \\
F9 & $1: 2: 2$ & 0.30 & $65.1 \pm 2.6$ & $92.3 \pm 3.5$ & $4.25 \pm 1.37$ & $150 \pm 5$ \\
\hline
\end{tabular}

Key: D:L:X = drug:locust bean gum:xanthan gum; DEE = drug entrapment efficiency

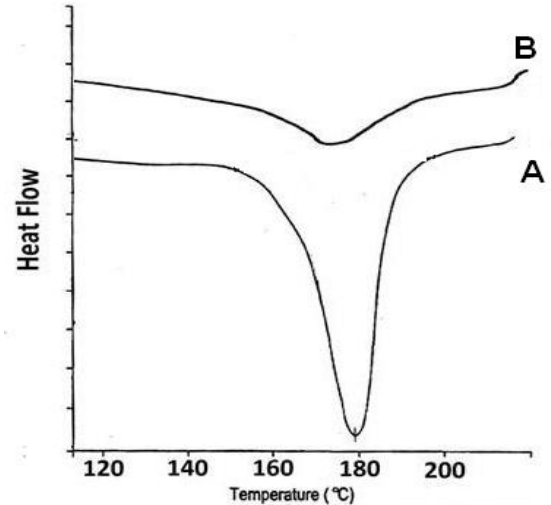

Figure 1: DSC thermograms of (A) pure esomeprazole magnesium and (B) drug-loaded microspheres (F6)

\section{Fourier Transform Infrared spectroscopy (FT- IR)}

The FT-IR spectra of the pure drug microsphere formulation (F6) are shown in Figure 2. The broad peak at $3217.01 \mathrm{~cm}^{-1}$ in the spectra of the pure drug corresponds to $\mathrm{C}=\mathrm{N}$ group. The peak at $108.32 \mathrm{~cm}^{-1}$ corresponds to $\mathrm{C}=\mathrm{S}$ boding. The peaks at $1613.2 \mathrm{~cm}^{-1}$ and $1581.2 \mathrm{~cm}^{-1}$ indicate the presence of carbonyl group. The drug and polymers employed were found to be compatible as similar peaks were observed with minor differences.

\section{In vitro drug release}

Figure 4 depicts the drug release profile of the various microsphere formulations. Increase in the content of polymer decreased drug release. Uncrosslinked microspheres showed significantly faster release than crosslinked formulations $(p<$ $0.05)$. Based on the correlation coefficient $\left(R^{2}\right)$ values, drug release was zero order and drug release mechanism showed a good fit to Korsmeyer Peppas model (Table 2). The diffusion exponent ' $n$ ' was $>0.85$ indicating that the formulations showed super case II transport kinetics, which mean that more than one mechanism may be involved in the drug release, i.e., drug release by diffusion, erosion and polymer chain relaxation.

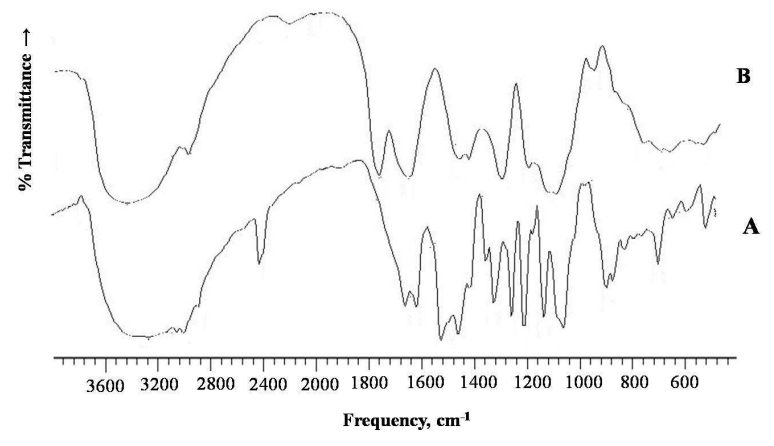

Figure 2: FT-IR spectra of (A) pure esomeprazole magnesium and (B) microsphere formulation (F6)

Scanning electron microscopy

The microspheres appeared to be spherical and discrete, as shown in Figure 3.

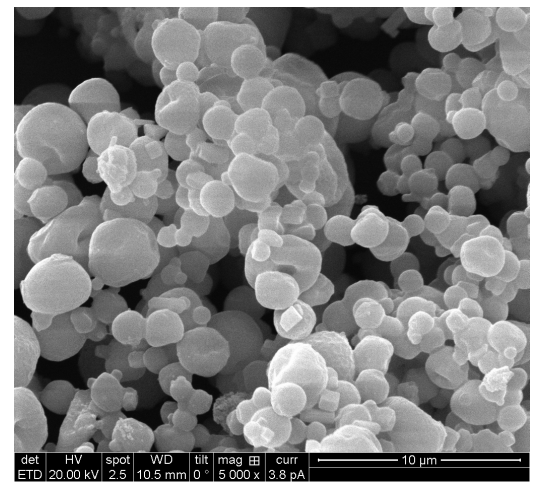

Figure 3: Scanning electron micrographs of microsphere formulation F6; 5000 x magnification 
Table 2: Kinetic release data of mucoadhesive microspheres

\begin{tabular}{cccccc}
\hline $\begin{array}{c}\text { Formulation } \\
\text { code }\end{array}$ & Zero order & First order & Higuchi & $\begin{array}{c}\text { Korsmeyer- } \\
\text { Peppas }\end{array}$ & $\boldsymbol{n}$ \\
\hline F1 & 0.8732 & 0.7125 & 0.6523 & 0.9145 & 0.9345 \\
F2 & 0.8784 & 0.7632 & 0.6589 & 0.9567 & 1.1102 \\
F3 & 0.8123 & 0.7741 & 0.7123 & 0.9894 & 0.9864 \\
F4 & 0.8720 & 0.7489 & 0.6589 & 0.9103 & 0.9956 \\
F5 & 0.8111 & 0.7852 & 0.6656 & 0.9456 & 1.1506 \\
F6 & 0.8123 & 0.7413 & 0.5789 & 0.8956 & 1.1023 \\
F7 & 0.8746 & 0.7631 & 0.6952 & 0.9666 & 0.9923 \\
F8 & 0.8560 & 0.7789 & 0.6854 & 0.9742 & 0.9658 \\
F9 & 0.8314 & 0.8120 & 0.7100 & 0.9856 & 1.1450 \\
\hline
\end{tabular}

\section{In vitro drug release}

Figure 4 depicts the drug release profile of the various microsphere formulations. Increase in the content of polymer decreased drug release. Uncrosslinked microspheres showed significantly faster release than crosslinked formulations $(p<$ $0.05)$. Based on the correlation coefficient $\left(R^{2}\right)$ values, drug release was zero order and drug release mechanism showed a good fit to Korsmeyer Peppas model (Table 2). The diffusion exponent ' $n$ ' was $>0.85$ indicating that the formulations showed super case II transport kinetics, which mean that more than one mechanism may be involved in the drug release, i.e., drug release by diffusion, erosion and polymer chain relaxation.

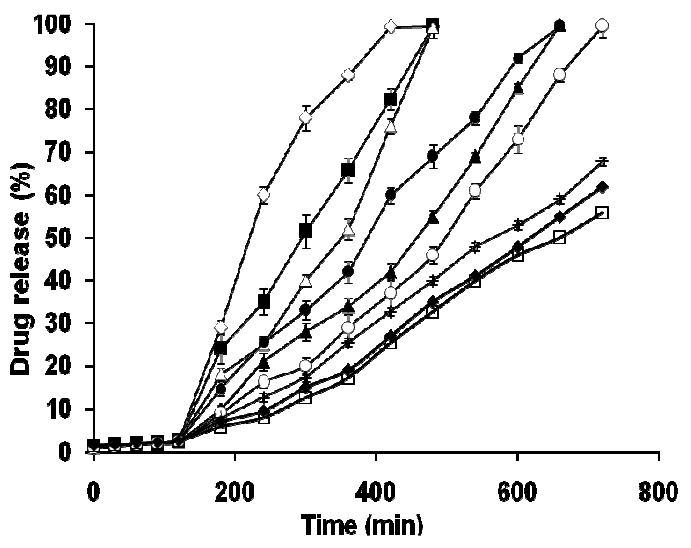

Figure 4: In vitro release profiles of esomeprazole magnesium microsphere formulations F1 $(\diamond), F 2(\mathbf{\square})$, F3 $(\Delta)$, F4 $(\bullet)$, F5 $(\Delta)$, F6 (o), F7 (+), F8 (•) and F9 $(\square)$; mean \pm standard deviation $(n=3)$

\section{DISCUSSION}

Drug entrapment efficiency (DEE) depended on the extent of crosslinking between cross linking agent and the gums. This can be attributed to the fact that higher extent of cross linking resulted in formation of a more rigid network structure which prevented the leaching out of drug during preparation of microspheres.

Increase in polymer concentration increased microsphere size. This may be due to increased viscosity leading to formation of bigger droplets. On the other hand, the decrease in particle size with increasing in the extent of crosslinking suggests that during crosslinking, the polymeric network transforms to a rigid network which is associated with shrinkage [12].

Formulations of uncrosslinked microspheres showed burst release which can be explained by rapid swelling followed by erosion unlike crosslinked microspheres. Swellability data revealed that the amount of polymer and crosslinker played an important role in solvent transfer. As the concentration of polymer increased, erosion reduces and hence swelling becomes greater. However, swelling decreased with increased crosslinking density, as much tighter networks are formed at higher concentration of crosslinking agent. At lower crosslink density, the network is loose with a greater hydrodynamic free volume, such that the chains can accommodate more of the solvent molecules, resulting in higher swelling. The swelling results are supported by the in vitro drug release data obtained [13] and similar findings elsewhere [9].

Non-aggregated microspheres with spherical shape were observed. Absence of crystalline structures on the surface of the microspheres indicates that esomeprazole magnesium was well dispersed inside the carrier.

The lack of disappearance of or significant shift in the peak position of drug in the FT-IR spectra of the drug and their corresponding DSC 
thermograms is an indication that the drug and polymers used for the study are compatible.

As the polymer content of the of the microspheres increased, the extent of drug release decreased. For the first two hours, the release was negligible (<5\%) for all the formulations. This is due to the enteric nature of Eudragit $\mathrm{L} 100$ which dissolves only in $\mathrm{pH}>6.0$. The uncrosslinked microspheres (F1, F2 and F3) showed complete release by the end of $8 \mathrm{~h}$. Crosslinked microspheres with $0.15 \%$ glutaraldehyde (F4, F5 and F6) showed cumulative drug release $(\mathrm{CDR})>85 \%$ at the end of $12 \mathrm{~h}$. Crosslinked microspheres containing $0.30 \%$ glutaraldehyde shows (F7, F8 \& F9 ) showed incomplete release at the end of $12 \mathrm{~h}$. The above release patterns correlate with swelling.

Super Case II transport is reported to be exhibited when diffusion and relaxation rates are comparable. In general, relaxational contribution was probably higher for formulations with higher Korsemeyer-Peppas ' $n$ ' value coupled with swelling and erosion which can be attributed to the hydrophilic gums. Hence, it can be suggested that the sustained release was achieved due to the slow erosion of the crosslinked polymers.

\section{CONCLUSION}

Crosslinked esomeprazole magnesium microspheres prepared with locust bean and xanthan gums by spray drying technique showed sustained release properties. However, further studies are required to evaluate the microspheres in vivo and to determine their toxicological and safety profiles.

\section{REFERENCES}

1. Longer MA, Ching HS, Robinson JR. Bioadhesive polymers as platforms for oral controlled drug delivery III: oral delivery of chlorothiazide using a bioadhesive polymer. J Pharm Sci 1985; 74(4): 406-411.

2. Chen CY. Lu CL. Luo JC. Chang FY. Lee SD, Lai YL. Esomeprazole tablet vs omeprazole capsule in treating erosive esophagitis. World $\mathrm{J}$ Gastroenterol., 2005, 11, 3112-3117.

3. Parmar H, Bakliwal S, Gujarathi N, Rane B, Pawar S. Different methods of formulation and evaluation of Mucoadhesive microsphere. Int J Appl Bio Pharm Tech 2010; 1(3): 1157- 1166.

4. What is Zollinger - Ellison syndrome? What causes Zollinger Ellision syndrome? Medical news today: [cited 2011 Sep 16]. Available from: http://www.medicalnewstoday.com/articles/186793. php

5. Scott LJ, Dunn CJ, Mallarkey G, Sharpe M. Esomeprazole: a review of its use in the management of acid-related disorders. Drugs 2002; 62(10): 1503-1538.

6. Locust bean gum powder [homepage on internet] Glyconutrition for life [cited 2011 July 29] http://www. glyconutritionforlife.org/Science of Glyc onutrients/Locust_Bean_Gum_Powder.php

7. Verbeken D, Dierckx S, Dewettinck K. Exudate gums: occurrence, production, and applications. Appl Microbiol Biotechnol 2003; 63: 10-21.

8. Garcia OF, Santos VE, Casas JA, Gomez E. Research review paper Xanthan gum: production, recovery, and properties. Biotech Adv 2000; 18: 549-579.

9. Nagda CD, Chotai NP, Nagda DC, Patel SB, Patel UL. Preparation and characterization of spray-dried mucoadhesive microspheres of ketorolac for nasal administration. Curr Drug Del 2012; 9: 205-218.

10. Ray S, Banerjee S, Maiti S, Laha B, Barik S, Sa B, Bhattacharyya UK. Novel interpenetrating network microspheres of xanthan gum-poly(vinyl alcohol) for the delivery of diclofenac sodium to the intestine--in vitro and in vivo evaluation. Drug Deliv 2010; 17 : 508-519.

11. Peppas NA. Analysis of Fickian and non-Fickian drug release from polymers. Pharm. Acta Helv 1985; 60:110-111.

12. Agnihotri SA, Aminbhavi TM. Controlled release of clozapine through chitosan microparticles prepared by a novel method. J Control Release 2004; 96: 245-259.

13. Umadevi SK, Thiruganesh $R$, Suresh $S$, Reddy $K B$. Formulation and evaluation of chitosan microspheres of aceclofenac for colon-targeted drug delivery. Biopharm Drug Dispos. 2010; 31: 407-427. 